\title{
ECTOMICORRIZA NO CRESCIMENTO DE Eucalyptus saligna EM SOLO CONTAMINADO COM COBRE
}

\section{ECTOMYCORHYZA ON THE GROWTH OF Eucalyptus saligna IN SOIL CONTAMINATED WITH COPPER}

\author{
Alex Dellai ${ }^{1}$ Rodrigo Ferreira da Silva ${ }^{2}$ Robson Andreazza ${ }^{3}$
}

\begin{abstract}
RESUMO
O cobre é um micronutriente essencial às plantas, contudo, em alta concentração no solo pode causar efeito tóxico. O objetivo deste trabalho foi determinar a influência da inoculação de Pisolithus microcarpus no crescimento de mudas de Eucalyptus saligna produzidas em solo contaminado com cobre. O delineamento experimental foi o inteiramente casualizado em arranjo fatorial ( $4 \times 2)$, quatro doses de cobre aplicadas ao solo (zero: teor natural do solo, 150, 300 e $450 \mathrm{mg} \mathrm{kg}^{-1}$ ), com e sem inoculação de fungo ectomicorrízico, com cinco repetições. Os parâmetros avaliados foram: altura de planta, diâmetro do colo, massa seca da parte aérea, massa seca radicular, comprimento da raiz principal, percentagem de colonização e os índices de qualidade de mudas: relação entre a altura de plantas e diâmetro do colo e o índice de qualidade de Dickson. A adição de até $118 \mathrm{mg} \mathrm{kg}^{-1}$ de cobre aumenta a massa seca radicular das mudas de Eucalyptus saligna produzidas em Latossolo com $81 \%$ de argila. A inoculação com o fungo ectomicorrízico Pisolithus microcarpus proporciona maior altura e massa seca da parte aérea das mudas de Eucalyptus saligna em doses elevadas de cobre no solo. Isto demonstra possibilidade de utilização deste fungo no reflorestamento de Eucalyptus saligna em áreas contaminadas com cobre.
\end{abstract}

Palavras-chave: áreas contaminadas com cobre; biorremediação; simbiose micorrízica.

\begin{abstract}
Copper is an essential micronutrient to plants. However, in high concentrations in the soil it can cause toxic effects. The aim of this study was to determine the influence of inoculation with Pisolithus microcarpus on the growth of Eucalyptus saligna seedlings grown in soil contaminated with copper. The experimental design was completely randomized in a factorial arrangement $(4 \times 2)$ four copper doses applied to the soil (zero: natural soil content, 150, 300 and $450 \mathrm{mg} \mathrm{kg}^{-1}$ ) and with and without fungi inoculation ectomycorrhizal, with five repetitions. The evaluated parameters were plant height, stem diameter, shoot dry mass, root dry mass, main root length, percentage of root colonization and quality indices of seedlings: relationship between plant height and stem diameter and Dickson quality index. The addition of $118 \mathrm{mg} \mathrm{kg}^{-1}$ of copper increased root dry mass of seedlings of Eucalyptus saligna produced in Oxisol with $81 \%$ of clay. The inoculation with the ectomycorrhizal fungus Pisolithus microcarpus provides greater height and dry mass of shoots of seedlings of Eucalyptus saligna in high doses of copper in the soil. This demonstrates the possibility of using the fungus Pisolithus microcarpus in the reforestation with Eucalyptus saligna in areas contaminated with copper.
\end{abstract}

Keywords: copper-contaminated sites; bioremediation; mycorrhizal symbiosis.

1 Engenheiro Agrônomo, MSc., CVALE Cooperativa Agroindustrial, Rua José Bonifácio 615, CEP 98300-000, Palmeira das Missões (RS), Brasil. Adellai2@yahoo.com

2 Engenheiro Agrônomo, Dr., Professor da Universidade Federal de Santa Maria, BR 386, Km 40, Linha 7 de setembro, s/n, CEP 98400-000, Frederico Westphalen (RS), Brasil. rodrigosilva@smail.ufsm.br

3 Engenheiro Agrônomo, Dr., Professor do Centro de Engenharias, Universidade Federal de Pelotas, Rua Benjamin Constant, 989, CEP 96010-020, Pelotas (RS), Brasil. robsonandreazza@yahoo.com.br

Recebido para publicação em 28/11/2013 e aceito em 5/04/2017

Ci. Fl., v. 28, n. 2, abr .- jun., 2018 


\section{INTRODUÇÃO}

Áreas contaminadas com cobre vêm aumentando no Brasil, dentre as quais, podem ser destacadas as de mineração e de vitivinicultura (CHAIGNON; HINSINGER, 2003; NACHTIGALL et al., 2007; SILVA et al., 2012; ANDREAZZA et al., 2013). O cobre é um elemento essencial ao desenvolvimento das plantas (DECHEN; NACHTIGALL, 2006), no entanto, quando em excesso no solo, podem causar inibição no crescimento, bem como alterar a comunidade de microrganismos (VANGRONSVELD; COLPAERT; TICHELEN, 1997; CHEN et al., 2003), ocasionando redução no crescimento vegetal.

Os fungos ectomicorrizicos formam associação simbiótica com plantas arbóreas. Ao se associarem com o sistema radicular das plantas, aumentam a absorção de água e nutrientes do solo e ao mesmo tempo em que a existência do manto fúngico, localizado na superfície das raízes, atua como uma barreira física e química a metais pesados (MOREIRA; SIQUEIRA, 2006; SMITH; READ, 2008). Dessa maneira, a simbiose ectomicorrízica pode auxiliar no desenvolvimento de espécies florestais em solo contaminado com metais pesados, possibilitando o aproveitamento de áreas contaminadas por cobre (SILVA et al., 2010).

O eucalipto possui capacidade de formar associação com fungos ectomicorrízicos (MELLO et al., 2006). Além disso, diversas pesquisas têm indicado a contribuição da associação ectomicorrízica no desenvolvimento de plantas em solo contaminado, como os estudos realizados por Gandini (2011) que, trabalhando com mudas clonais de Eucalyptus urophylla, observou maior diâmetro do colo, altura e massa seca da parte aérea nas mudas inoculadas com fungos ectomicorrízicos. Antoniolli et al. (2010) observaram efeito positivo do fungo Pisolithus microcarpus na altura, massa fresca radicular e aérea em mudas de Eucalyptus grandis. Diante disso pode-se inferir que a inoculação com fungos ectomicorrízicos contribui para o desenvolvimento de mudas de eucalipto.

As áreas de plantios com espécies exóticas para reflorestamento estão aumentando no Brasil, visando ao fornecimento de madeira para energia, dormentes, papel e polpa (MAÇANEIRO; SEUBERT; AUMOND, 2013). Entretanto, as áreas cultivadas com essas essências florestais não estão suprindo o volume de madeira requerido (ROSSI, 2006). Dessa maneira, alternativas que possibilitem o desenvolvimento de arbóreas florestais em solo contaminado por cobre pode contribuir para o aumento da oferta de madeira para as indústrias de celulose, produção de energia e outros produtos.

O gênero Eucalyptus é originário da Austrália, sendo considerada uma das principais arbóreas florestais encontradas no Brasil, correspondendo a $81.2 \%$ das espécies plantadas e, isso se deve a sua adaptabilidade e seu potencial produtivo (GARAY et al., 2004; TREVISAN et al., 2007; BRASELPA, 2012). O Eucalyptus saligna representa $17 \%$ dos 2.9 milhões de hectares de florestas plantadas no Brasil (CAMPOS et al., 2011), essa espécie apresenta densidade de $0.55 \mathrm{~g} \mathrm{~cm}^{3}$ aos 16 anos de idade (OLIVEIRA; SILVA, 2003), sendo superior às densidades das espécies do gênero Pinus, tornando-se uma espécie interessante para a produção de painéis compensados (IWAKIR et al., 2012). Assim, estudos que contemplam avaliar o efeito da micorrização no Eucalyptus saligna e seu desenvolvimento em solo contaminado por metais ganham importância para aumentar a oferta de madeira e utilizar áreas degradadas com fins lucrativos. $\mathrm{O}$ objetivo desse trabalho foi determinar a influência de Pisolithus microcarpus em mudas de Eucalyptus saligna cultivadas em solo contaminado com cobre.

\section{MATERIAS E MÉTODOS}

O trabalho foi desenvolvido durante 180 dias em casa de vegetação, com solo classificado como Latossolo Vermelho Distrófico (EMBRAPA, 1999), com as seguintes características físicas e químicas: $\mathrm{pH}$ água : 4,9; $\mathrm{Ca}+\mathrm{Mg}=5,4 \mathrm{cmol}_{\mathrm{c}} \mathrm{kg}^{-1} ; \mathrm{Al}=4,3 \mathrm{cmol}_{\mathrm{c}} \mathrm{kg}^{-1} ; \mathrm{H}+\mathrm{Al}=6,6 \mathrm{cmol}_{\mathrm{c}} \mathrm{Kg}^{-1} ; \mathrm{P}=6,6 \mathrm{mg} \mathrm{dm}^{-3} ; \mathrm{K}=111,0$ mg dm${ }^{-3} ; \mathrm{Zn}=1,6 \mathrm{mg} \mathrm{dm}^{-3} ; \mathrm{Cu}_{\text {disponivel }}=15,1 \mathrm{mg} \mathrm{dm}^{-3} ;$ matéria orgânica $=2,4 \%$; e argila $=81 \%$. O solo passou por três ciclos de esterilização em autoclave, de 30 minutos a $121^{\circ} \mathrm{C}$.

O fungo ectomicorrízico inoculado nas mudas foi o UFSC-Pt116 (Pisolithus microcarpus) obtido na Universidade Federal de Santa Catarina. O fungo foi multiplicado no meio MNM sólido (Melin-Norkrans Modificado) (MARX, 1969), em placas de Petri, submetido a BOD a $25^{\circ} \mathrm{C}$. Na preparação do inoculante utilizou-se o micélio fúngico de duas placas de Petri, o qual foi triturado em liquidificador com $600 \mathrm{~mL}$ de água destilada por 10 segundos. Para inoculação foi aplicado $2 \mathrm{~mL}$ dessa solução, por meio de uma seringa 
graduada, diretamente no solo de cada tratamento. Quinze dias após emergência das plantas, iniciou-se as inoculações, sendo realizadas em intervalos de 15 dias, totalizando 5 inoculações. A testemunha sem inoculação, também recebeu $2 \mathrm{~mL}$ de uma solução contendo somente o meio de cultura MNM.

Para o desenvolvimento do trabalho utilizou-se o Eucalyptus saligna. As unidades experimentais foram tubetes com volume contendo uma planta. Inicialmente semeou-se 5 sementes por tubete de $96 \mathrm{~cm}^{3}$ e 10 dias após a emergência realizou-se o desbaste, deixando-se uma planta por unidade experimental. O delineamento experimental foi inteiramente casualizado em arranjo fatorial (4 x 2), sendo quatro doses de cobre (zero: teor natural do solo, 150,300 e $450 \mathrm{mg} \mathrm{kg}^{-1}$ ), com ou sem inoculação de fungo ectomicorrízico, com cinco repetições. A contaminação do solo foi por meio da adição de sulfato de cobre $\left(\mathrm{CuSO}_{4} \cdot 5 \mathrm{H}_{2} \mathrm{O}\right)$.

Avaliou-se os parâmetros altura de planta (AP), diâmetro do colo (DC), massa seca da parte aérea (MSPA), massa seca radicular (MSPR), comprimento da raiz principal (CRP), percentagem de colonização radicular (PCR). A altura de planta e o comprimento da raiz principal foram avaliados com régua graduada de $30 \mathrm{~cm}$. O diâmetro do colo foi mensurado com paquímetro digital. Por meio de um corte na região do colo da muda separou-se a parte aérea da parte radicular, as quais foram submetidas à estufa com circulação forçada de ar, à temperatura de $65^{\circ} \mathrm{C}$ até peso constante, sendo pesadas em balança analítica obtendo-se a massa seca da arte aérea e a massa seca radicular.

Com base nos parâmetros morfológicos avaliados também foram calculados índices de qualidade de mudas como a relação entre a altura de plantas (AP) e diâmetro do colo (DC) e o índice de qualidade de Dickson (DICKSON; LEAF; HOSNER, 1960), por meio da fórmula: IQD = (MSPA + MSPR) (g)/ $[\mathrm{AP}(\mathrm{cm}) / \mathrm{DC}(\mathrm{mm})]+[\mathrm{MSPA}(\mathrm{g}) / \mathrm{MSPR}(\mathrm{g})]$.

Após a técnica de clareamento e coloração das raízes foi calculado o percentual de colonização radicular, utilizando a equação $\mathrm{CM}=\left(\mathrm{n}^{\circ}\right.$ total de raízes colonizadas $/ \mathrm{n}^{\circ}$ total de raízes $)$ x 100 (BRINDRETT et al., 1996).

Os dados foram submetidos à análise de variância e quando houve interação significativa desdobraram-se as doses dentro de cada tratamento de inoculação, por meio de regressões polinomiais. Quando não houve interação, analisaram-se os efeitos simples por Tukey (tratamento inoculação) e equações de regressão (doses) com nível de significância maior que $95 \%(\mathrm{p}<0,05)$, por meio do programa SISVAR (FERREIRA, 2006).

\section{RESULTADOS E DISCUSSÃO}

Os resultados evidenciaram interação significativa entre os fatores de variação doses e inoculação para a altura, massa seca da parte aérea, porcentagem de colonização radicular e relação altura/diâmetro do colo nas mudas de Eucalyptus saligna (Tabela 1; Figura 1). O cobre influenciou negativamente a altura das mudas de eucalipto (Tabela 1). Entretanto, as mudas inoculadas apresentaram maior altura em relação as não inoculadas na maior dose de cobre (Figura 1A). Esse trabalho corrobora com os resultados de Steffen et al. (2011), em que mudas de Eucalyptus grandis produzidas em solo arenoso contaminado com cobre apresentaram maior altura, quando inoculadas com o isolado UFSC-Pt116. O resultado deste trabalho demonstra que a inoculação do isolado ectomicorrízico possibilita maior altura do Eucalyptus saligna produzido em solo contaminado.

A massa seca da parte área foi significativamente maior com a presença do fungo ectomicorrízico nos tratamentos controle e com adição de $450 \mathrm{mg} \mathrm{kg}^{-1}$ de cobre (Tabela 1). Embora tenha ocorrido redução da massa seca da parte aérea com as doses de cobre, na presença do fungo ectomicorrízico, observase incremento de $18,4 \%$ e $70,3 \%$ no tratamento sem aplicação de cobre e com adição de $450 \mathrm{mg} \mathrm{kg}^{-1}$, respectivamente, em relação ao tratamento sem inoculado (Figura 1B). De acordo com Souza (2003), a massa seca de ramos e folhas é o parâmetro mais importante em estudos em que se verifica a eficiência de determinadas variáveis sobre o desenvolvimento e crescimento vegetal. Os resultados deste trabalho evidenciam resposta positiva da inoculação com o fungo ectomicorrízico no estímulo ao crescimento de mudas de Eucalyptus saligna em contaminado com cobre. 
TABELA 1: Altura, massa seca da parte aérea (MSPA), porcentagem de colonização radicular (PCR) e relação altura/diâmetro do colo (H/D) de mudas de Eucalyptus saligna cultivada em doses de cobre, com e sem inoculação do fungo ectomicorrízico Pisolithus microcarpus.

TABLE 1: Height, shoot dry mass (SDM), percentage of root colonization (PRC) and ratio of height/stem diameter (H/D) of Eucalyptus saligna grown in copper concentrations, and with and without inoculation of ectomycorrhizal fungus Pisolithus microcarpus.

\begin{tabular}{|c|c|c|c|c|c|}
\hline \multirow[t]{2}{*}{ Inoculação } & \multicolumn{4}{|c|}{ Doses de $\mathrm{Cu}\left(\mathrm{mg} \mathrm{kg}^{-1}\right)$} & \multirow[t]{2}{*}{$\mathrm{CV} \%$} \\
\hline & $0^{1}$ & 150 & 300 & 450 & \\
\hline & & - & $\operatorname{ara}(\mathrm{cm})$ & & ---- \\
\hline Com Fungo & $18,9 \mathrm{Aa}^{*}$ & $16,9 \mathrm{Ab}$ & $12,9 \mathrm{Ac}$ & $8,7 \mathrm{Ad}$ & \multirow{2}{*}{8,36} \\
\hline Sem Fungo & $16,5 \mathrm{Ba}$ & $16,9 \mathrm{Aa}$ & $13,9 \mathrm{Ab}$ & $5,7 \mathrm{Bc}$ & \\
\hline Com Fungo & $0,505 \mathrm{Aa}$ & $0,510 \mathrm{Aa}$ & $0,294 \mathrm{Ab}$ & $0,222 \mathrm{Ab}$ & \multirow{2}{*}{19,37} \\
\hline Sem Fungo & $0,412 \mathrm{Bb}$ & $0,558 \mathrm{Aa}$ & $0,260 \mathrm{Ab}$ & $0,066 \mathrm{Bc}$ & \\
\hline Com Fungo & $16,2 \mathrm{Aa}$ & $16.60 \mathrm{Aa}$ & $\begin{array}{r}\mathrm{C}(\%) \\
1080 \mathrm{Ab}\end{array}$ & $8.60 \mathrm{Ac}$ & \multirow[b]{2}{*}{9,67} \\
\hline Sem Fungo & $0 \mathrm{Ba}$ & $0 \mathrm{Ba}$ & $0 \mathrm{Ba}$ & $0 \mathrm{Bb}$ & \\
\hline Com Fungo & $9,39 \mathrm{Ab}$ & $7,60 \mathrm{Ab}$ & $7,67 \mathrm{Ab}$ & $15,96 \mathrm{Aa}$ & \multirow[b]{2}{*}{13,44} \\
\hline Sem Fungo & 7,56 Bab & $8,80 \mathrm{Aa}$ & $8,65 \mathrm{Aab}$ & $6,67 \mathrm{Bb}$ & \\
\hline
\end{tabular}

Em que: Médias seguidas de mesma letra maiúscula na coluna e minúscula na linha não diferem entre si pelo teste de Tukey 5\% de probabilidade de erro. ${ }^{1}$ Teor natural do solo: $15,1 \mathrm{mg} \mathrm{Cu} \mathrm{dm}^{-3}$ de solo; $\mathrm{CV} \%$ : Coeficiente de variação \%.
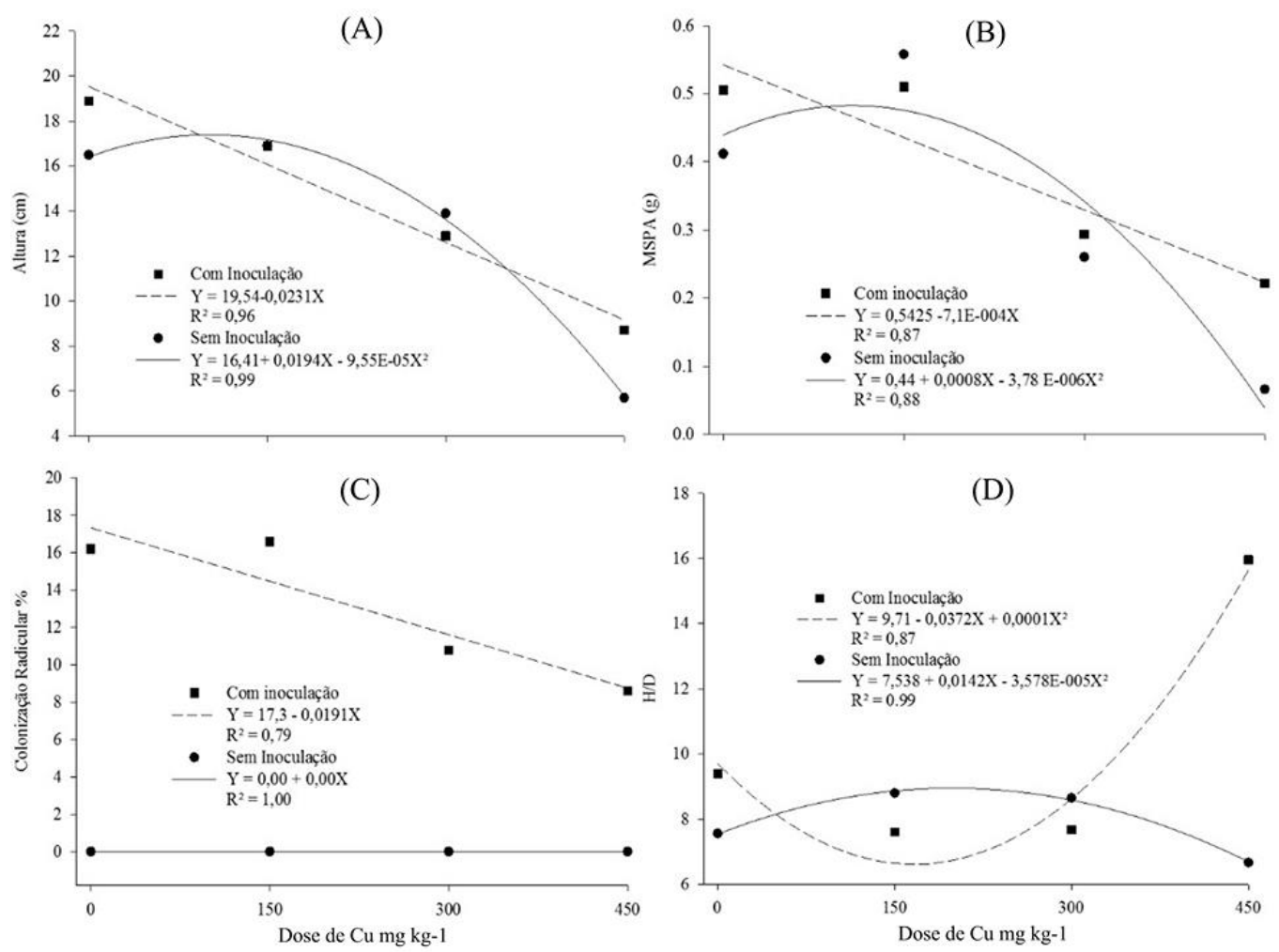

FIGURA 1: Altura de planta (A), massa seca de parte aérea (MSPA) (B), percentual de colonização radicular (C) e relação altura diâmetro (H/D) de mudas de Eucalyptus saligna produzida nas diferentes doses de cobre, com e sem inoculação de fungo ectomicorrízico Pisolithus microcarpus.

FIGURE 1: Plant height (A), dry mass of the shoots (DMS) (B), percentage of root colonization (C) and ratio of height/stem diameter (D) of Eucalyptus saligna grown in different doses of copper, with and without inoculation of ectomycorrhizal fungus Pisolithus microcarpus. 
No que se refere à colonização radicular, observar-se que o Eucalyptus saligna formou associação ectomicorrízica com isolado UFSC-Pt116 (Tabela 1). No entanto, os resultados indicam que o cobre reduziu linearmente a porcentagem de colonização radicular (Figura 1C). Steffen et al. (2011) também obtiveram percentagem de colonização radicular em torno de $20 \%$ nas raízes de Eucalyptus grandis colonizadas pelo isolado UFSC-Pt116, resultando em incremento do crescimento das mudas. Outros autores encontraram porcentagem de colonização radicular similares aos deste trabalho, ou seja, $21.7 \%$ em plantios jovens de eucalipto (CAMPOS et al., 2011). Desse modo, mesmo que as doses de cobre tenham reduzido o percentual de colonização radicular, a ectomicorriza pode auxiliar o desenvolvimento de Eucalyptus saligna, pois possibilitou maior massa seca da parte aérea e altura de mudas (Tabela 1).

A inoculação com o isolado ectomicorrízico proporcionou maior relação $\mathrm{H} / \mathrm{D}$ em relação ao tratamento sem inoculação na dose zero e com $450 \mathrm{mg} \mathrm{kg}^{-1}$ (Tabela 1; Figura 1D), evidenciando que a utilização do isolado é eficiente para melhorar a relação H/D. De acordo com Carneiro (1995), o valor ideal desta relação está entre 5,4 a 8,1, pois possibilita um desenvolvimento equilibrado com melhor qualidade de plantio (MARANHO; PAIVA, 2011). Nesse caso, a inoculação com Pisolithus microcarpus foi significativamente benéfica para essa relação nas doses 150 e $300 \mathrm{mg} \mathrm{kg}^{-1}$ de cobre (Tabela 1, Figura 1D). Dessa forma, a inoculação das plantas de Eucalyptus saligna resultou em uma relação H/D adequada para o transplante em solos contaminados com doses entre 150 e $300 \mathrm{mg} \mathrm{kg}^{-1}$ de cobre.

Não foi observada interação significativa entre os tratamentos qualitativos e quantitativos para os parâmetros diâmetro do colo, comprimento da raiz principal, massa seca da parte radicular e índice de qualidade de mudas (Tabela 2). Ao serem analisados os efeitos simples para o tratamento inoculação, não foi observada diferença significativa para o diâmetro do colo, massa seca da parte radicular e índice de qualidade de Dickson. No entanto, o comprimento da raiz principal foi significativamente menor no tratamento com a inoculação do fungo ectomicorrízico. Embora haja redução no sistema radicular provocado pela formação da ectomicorriza, o resultado final dessa associação é o aumento da área de absorção radicular da planta por causa da presença das hifas do fungo (SMITH; READ, 2008), possibilitando o crescimento de plantas em solos degradados e com baixa disponibilidade de nutrientes (BERTOLAZI et al., 2010).

TABELA 2: Diâmetro do colo, comprimento da raiz principal (CRP), massa seca da parte radicular e índice de qualidade de mudas (IQD) de mudas de Eucalyptus saligna com e sem inoculação do fungo ectomicorrízico Pisolithus microcarpus.

TABLE 2: Stem diameter, the main root length (CRP), dry weight of roots (MSPR) and seedling quality index (IQD) of Eucalyptus saligna with and without inoculation of the ectomycorrhizal fungus Pisolithus microcarpus.

\begin{tabular}{ccccc}
\hline Tratamentos & \multicolumn{4}{c}{ Parâmetros sem interação significativa } \\
& Diâmetro & CRP & MSPR & IQD \\
\hline Com fungo & $1,65^{\mathrm{ns}}$ & $14,64 \mathrm{~b}$ & $0,20^{\mathrm{ns}}$ & $0,06^{\mathrm{ns}}$ \\
Sem fungo & $1,65^{\mathrm{ns}}$ & $14,81 \mathrm{a}$ & $0,24^{\mathrm{ns}}$ & $0,06^{\mathrm{ns}}$ \\
CV\% & 17,6 & 0,44 & 6,55 & 18,71 \\
\hline
\end{tabular}

Em que: Valores seguidos de mesma letra (com e sem inoculação) não diferem pelo teste de Tukey a 5\% de probabilidade de erro; ns = não significativo.

O Diâmetro do colo e o comprimento da raiz principal apresentaram redução linear com o incremento das doses de cobre aplicadas ao solo (Figuras 2A e 2B), sendo que o diâmetro do colo apresentou redução de $67,5 \%$ na maior dose de cobre aplicada ao solo em relação ao tratamento sem aplicação de cobre (Figura 2A). De acordo com Yruela (2009), altas quantidades de cobre no solo causam toxidade às plantas como inibição no crescimento de raízes e redução da fotossíntese. Resultados semelhantes também foram evidenciados por Shah et al. (2011) que observaram redução no diâmetro do colo em mudas de Eucalyptus camaldulensis submetidas à aplicação de água residuária contaminada com cádmio e cromo. 

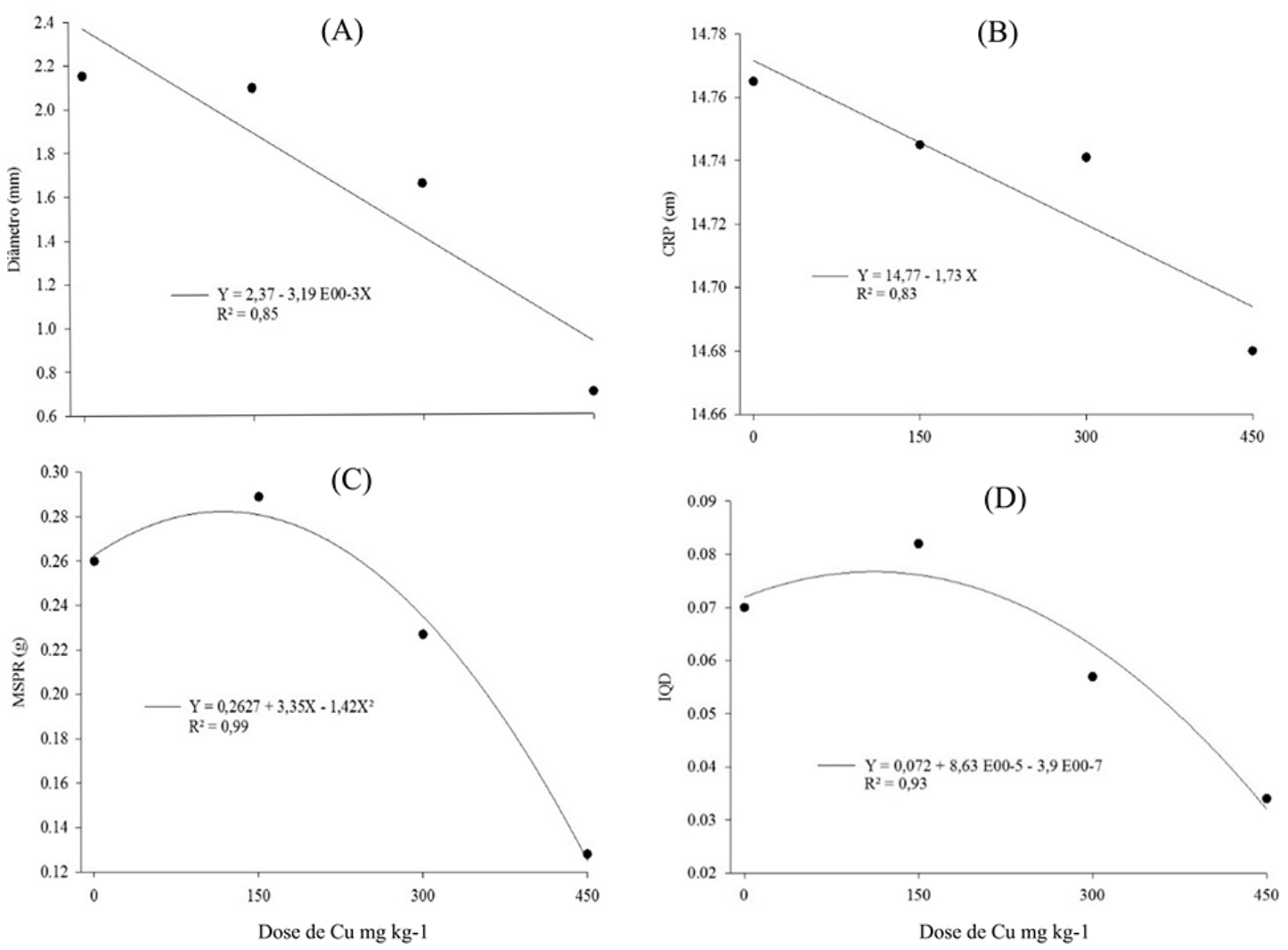

FIGURA 2: Diâmetro do colo (A), comprimento da raiz principal (B), massa seca da parte radicular (C) e índice de qualidade de mudas (D) de mudas de Eucalyptus saligna produzidas em solo com doses crescentes de cobre.

FIGURE 2: Stem diameter (A), the main root length (CRP) (B), dry weight of the roots (C) and seedling quality index (D) of the Eucalyptus saligna grown in soil with increasing doses of copper.

A massa seca da parte radicular apresentou ponto de máxima a $118 \mathrm{mg} \mathrm{kg}^{-1}$ de cobre, sendo que a maior dose de cobre aplicada ao solo causou a redução de 50,7 \% da MSPR em relação ao tratamento sem aplicação de cobre (Figura 2C). De acordo com Taiz e Zeiger (2012) o cobre quando presente em pequenas quantidades atua como catalisador de reações químicas, metabolismo de carboidratos e síntese de clorofila. Entretanto, quando em excesso, o cobre reduz a taxa fotossintética por interferir na cadeia transportadora de elétrons do fotossistema I, diminuindo a produção de fotoassimilados pelas plantas, ocasionando redução no crescimento vegetal (KABATA-PENDIAS; PENDIAS, 2001). Resultados observados por Caires et al. (2011) avaliando mudas de cedro-rosa produzidas em solo contaminado com doses crescentes de cobre, também evidenciaram ponto de máxima produção de MSPR e em seguida declínio na produção. Outro estudo, avaliando a produção de aveia-preta, demonstrou que solos de vitivinicultura contaminados com cobre (400 mg kg-1 de cobre), e rejeitos de mineração de cobre (575 $\mathrm{mg} \mathrm{kg}^{-1}$ de cobre) reduziram significativamente o crescimento das plantas (ANDREAZZA et al., 2010).

O índice de qualidade de mudas demonstrou ponto de máxima a 110,6 mg de $\mathrm{Cu} \mathrm{kg}^{-1}$ (Figura 2D). Devido a este índice levar em consideração a relação entre parâmetros importantes como altura de mudas, massa seca radicular e massa seca da parte aérea, observa-se neste trabalho que a massa seca da parte radicular também apresentou incremento com as doses iniciais de cobre (Figura 2C) e, isso não possibilitou o valor mínimo preconizado por Hunt (1990) de 0,2, entretanto, no ponto de máxima observou-se incremento 8.5\% nos valores do IQD em relação ao tratamento sem adição de cobre. Desse modo, é importante salientar que pequenas doses de cobre ao solo podem contribuir para o IQD de mudas de Eucalyptus saligna produzidas em Latossolo Vermelho distrófico com $81 \%$ de argila. 


\section{CONCLUSÕES}

Os resultados demonstram possibilidade de utilização do fungo Pisolithus microcarpus no reflorestamento de áreas contaminadas com cobre, melhorando as características de crescimento e adaptação das plantas de Eucalyptus saligna nestes ambientes.

\section{REFERÊNCIAS}

ANDREAZZA, R. et al. Biorremediação de áreas contaminadas com cobre. Revista de Ciências Agrárias, Lisboa, v. 36, p. 127-136, 2013.

ANDREAZZA, R. et al. Bacterial stimulation of copper phytoaccumulation by bioaugmentation with rhizosphere bacteria. Chemosphere, Oxford, v. 81, p. 1149-1155, 2010.

ANTONIOLLI, Z. I. et al. Efeito do cobre na população de bactérias e fungos do solo, na associação micorrízica e no cultivo de mudas de Eucalyptus grandis W. Hill ex Maiden, Pinus elliottii Engelm E Peltophorum dubium (Sprengel) Taubert. Ciência Florestal, Santa Maria, v. 20, p. 419-428, 2010.

BERTOLAZI, A. A. et al. O papel das ectomicorrizas na biorremediação de metais pesados no solo. Natureza Online, Santa Teresa, v. 8, p. 24-31, 2010.

ASSOCIAÇÃO BRASILEIRA DE CELULOSE E PAPEL. Relatório florestal 2010/2011. São Paulo: BRASELPA, 2012. Disponível em: <http://www.bracelpa.org.br/bra2/sites/default/files/public/RA02RelatorioFlorestal 2010.pdf>. Acesso em: 12 mar. 2013.

BRUNDRETT, M. et al. Working with mycorrhizas in forestry and agriculture. Canberra: ACIAR, 1996. $400 \mathrm{p}$.

CAIRES, S. M. et al. Desenvolvimento de mudas de cedro-rosa em solo contaminado com cobre: tolerância e potencial para fins de fitoestabilização do solo. Revista Árvore, Viçosa, MG, v. 35, p. 1181-1188, 2011. CAMPOS, D. T. S. et al. Colonização micorrízica em plantios de eucalipto. Revista Árvore, Viçosa, MG, v. 35, p. 965-974, 2011.

CARNEIRO, J. G. A. Produção e controle de qualidade de mudas florestais. Curitiba: UFPR; FUPEF, 1995. $451 \mathrm{p}$.

CHAIGNON, V.; HINSINGER, P. A. Biotest for evaluating for bioavailability to plants in a contaminated soil. Journal of Environment Quality, Madison, v. 32, p. 834-833, 2003.

CHEN, B. D. et al. The role of arbuscular mycorrhiza in zinc uptake by red clover growing in a calcareous soil spiked with various quantities of zinc. Chemosphere, Oxford, v. 50, p. 839-846, 2003.

DECHEN, A. R.; NACHTIGALL, G. R. Micronutrientes. In: Fernandes, M. S. (Ed.). Nutrição mineral de plantas. Viçosa, MG: Sociedade Brasileira de Ciência do Solo, 2006. p. 328-352.

DICKSON, A.; LEAF, A. L.; HOSNER, J. F. Quality appraisal of white spruce and white pine seedling stock in nurseries. Forest Chronicle, Mattawa, v. 36, p. 10-13, 1960.

EMBRAPA. Sistema brasileiro de classificação de solos. Brasília: Embrapa, 1999. 412 p.

FERREIRA, D. F. Sistemas de análise estatística para dados balanceados. Lavras: UFLA; DEX; SISVAR, 2006. 145 p.

GANDINI, A. M. M. Promoção do crescimento e da nutrição de mudas clonais de Eucalyptus urophylla por fungos ectomicorrízicos em viveiro comercial. 2011. 32 f. Dissertação (Mestrado em Produção Vegetal) - Universidade Federal dos Vales do Jequitinhonha e Mucuri, Diamantina, 2011.

GARAY, I. et al. Evaluation of soil conditions in fast-growing plantations of Eucalyptus grandis and Acacia mangium in Brazil: a contribution to the study of sustainable land use. Applied Soil Ecology, Dublin, v. 27, p. 177-187, 2004.

HUNT, G. A. Effect of styroblock design and copper treatment on morphology of conifer seedlings. In: ROSE, R.; CAMPBELL, S. J.; LANDIS, T. D. (Ed.). Proceedings, Western Forest Nursery Association. Roseburg, OR. General Technical Report RM-200. Fort Collins: U.S. Department of Agriculture, 1990. p. 218-222.

IWAKIRI, S. et al. Produção de painéis compensados estruturais com diferentes composições de lâminas de Eucalyptus saligna e Pinus caribaea. Revista Árvore, Viçosa, MG, v. 36, p. 569-576, 2012.

KABATA-PENDIAS, A.; PENDIAS, H. Trace elements in soils and plants. 3. ed. Boca Raton: CRC

Ci. Fl., v. 28, n. 2, abr .- jun., 2018 
Press, 2001. $315 \mathrm{p}$.

MAÇANEIRO, J. P.; SEUBERT, R. C; AUMOND, J. J. Aplicação de uma técnica alternativa de manejo físico do solo no cultivo de Eucalyptus grandis W.Hill (Myrtaceae). Revista Árvore, Viçosa, MG, v. 37, p. 9-18, 2013.

MARX, D. H. The influence of ectotrophic mycorrhizal fungi on the resistance of pine roots to pathogenic infections. I. Antagonism of mycorrhizal fungi to root pathogenic fungi and soil bacteria. Phytopathologist, Saint Paul, v. 59, p. 153-163, 1969.

MARANHO, Á. S; PAIVA, A. V.; Crescimento inicial de mudas de Senna silvestris (Vell.) H. S. Irwin \& Barneby cultivadas em diferentes substratos. Revista da Sociedade Brasileira de Arborização Urbana, Piracicaba, v. 6, p. 1-14, 2011.

MELLO, A. H. et al. Fungos arbusculares e ectomicorrízicos em áreas de eucalipto e de campo nativo em solo arenoso. Ciência Florestal, Santa Maria, v. 16, p. 293-301, 2006.

MOREIRA, F. M. S.; SIQUEIRA, J. O. S. Microbiologia e bioquímica do solo. Lavras: UFLA, 2006. 729 p.

NACHTIGALL, G. R. et al. Copper concentration of vineyard soils as a function of $\mathrm{pH}$ variation and addition of poultry litter. Brazilian Archives of Biology and Technology, Curitiba, v. 50, p. 941-948, 2007. OLIVEIRA, J. T. S.; SILVA, J. C. Variação radial da retratibilidade e densidade básica da madeira de Eucalyptus saligna Sm. Revista Árvore, Viçosa, MG, v. 27, p. 381-385, 2003.

ROSSI, M. J. Tecnologia para produção de inoculantes de fungos ectomicorrízicos utilizando cultivo submerso em biorreator airlift. 2006. 188 f. Tese (Doutorado em Engenharia Química) - Universidade Federal de Santa Catarina, Florianópolis, 2006.

SHAH, F. R. et al. Response of Eucalyptus camaldulensis to exogenous application of cadmium and chromium. Pakistan Journal of Botany, Karachi, v. 43, p. 181-189, 2011.

SILVA, R. F. et al. Crescimento e qualidade de mudas de Timbó e Dedaleiro cultivadas em solo contaminado por cobre. Revista Brasileira de Engenharia Agrícola e Ambiental, Campina Grande, v. 16, p. 881-886, 2012.

SILVA, R. F. et al. Tolerância de mudas de canafístula (Peltophorum dubium (Spreng.) Taub.) inoculada com Pisolithus microcarpus a solo com excesso de cobre. Ciência Florestal, Santa Maria, v. 20, p. 147156, 2010.

SMITH, S. E.; READ, D. J. Mycorrhizal symbiosis. 3. ed. San Diego: Academic Press, 2008. 787 p.

SOUZA, L. A. B. Seleção de fungos ectomicorrízicos eficientes para promoção do crescimento de Eucalyptus dunni Maiden. 2003. 100 f. Dissertação (Mestrado em Biotecnologia) - Universidade Federal de Santa Catarina, Florianópolis, 2003.

STEFFEN, R. B. et al. Ação do óleo essencial de eucalipto na micorrização e no estabelecimento de Eucalyptus grandis em solo contaminado por cobre. Pesquisa Florestal Brasileira, Colombo, v. 31, p. 245-255, 2011.

TAIZ, L.; ZEIGER, E. Fisiologia vegetal. 5. ed. Porto Alegre: Artmed, 2012. 954 p.

TENNANT, D. A test of a modified line intersect method of estimating root lengh. Journal of Ecology, London, Danvers, v. 63, p. 995-1001, 1975.

TREVISAN, R. et al. Efeito da intensidade de desbaste nas características dendrométricas e tecnológicas da madeira de Eucalyptus grandis. Ciência Florestal, Santa Maria, v. 17, p. 377-387, 2007.

VANGROSVELD, J.; COLPAERT, J. V.; TICHELEN, K. K. Reclamation of a bare industrial area contaminated by non-ferrous metals: physicochemical and biological evaluation of the durability of soil treatment and revegetation. Environmental Pollution, Oxford, v. 94, p. 131-140, 1997.

YRUELA, I. Copper in plants: acquisition, transport and interactions. Functional Plant Biology, Vitória, v. 36, p. 409-430, 2009. 